\title{
Optimal placement of Phasor Measurement Units to Improve Parallel Power System Restoration
}

DOI:

10.1109/ISGTEurope.2011.6162687

Link to publication record in Manchester Research Explorer

\section{Citation for published version (APA):}

Quirós Tortos, J., Valverde, G., Ding, L., \& Terzija, V. (2011). Optimal placement of Phasor Measurement Units to Improve Parallel Power System Restoration. In IEEE PES Innovative Smart Grid Technologies Conference Europe/IEEE PES Innovative. Smart Grid Technol. Conf. Europe IEEE. https://doi.org/10.1109/ISGTEurope.2011.6162687

\section{Published in:}

IEEE PES Innovative Smart Grid Technologies Conference Europe|IEEE PES Innovative. Smart Grid Technol. Conf. Europe

\section{Citing this paper}

Please note that where the full-text provided on Manchester Research Explorer is the Author Accepted Manuscript or Proof version this may differ from the final Published version. If citing, it is advised that you check and use the publisher's definitive version.

\section{General rights}

Copyright and moral rights for the publications made accessible in the Research Explorer are retained by the authors and/or other copyright owners and it is a condition of accessing publications that users recognise and abide by the legal requirements associated with these rights.

\section{Takedown policy}

If you believe that this document breaches copyright please refer to the University of Manchester's Takedown Procedures [http://man.ac.uk/04Y6Bo] or contact uml.scholarlycommunications@manchester.ac.uk providing relevant details, so we can investigate your claim.

\section{OPEN ACCESS}




\title{
Optimal Placement of Phasor Measurement Units to Improve Parallel Power System Restoration
}

\author{
J. Quirós Tortós, Student Member, IEEE, G. Valverde, Student Member, IEEE, L. Ding, Member, \\ IEEE, V. Terzija, Senior Member, IEEE
}

\begin{abstract}
This paper proposes a new method for optimal placement of Phasor Measurement Units (PMUs) across the weak areas of the power system to monitor the status of the boundary buses during Parallel Power System Restoration (PPSR). The proposed PMU placement method is based on an Integer Linear Programming (ILP) methodology. For validation purposes, the proposed method is implemented across the weak areas of the following two test systems: New England 39-bus test system and IEEE 118-bus test system.
\end{abstract}

Index Terms--Parallel power system restoration, phasor measurement unit, power system restoration, slow coherency, synchronised measurement technology, weak area, weak connection.

\section{INTRODUCTION}

$\mathrm{T}$ HE lack of information during parallel power system restoration has been previously claimed as one of major concerns for power system operators. When restoring a power system, the assessment of the status of the perturbed network must be carried out first [1]. This is followed by the reconnection of various generation units and the subsequent identification of restoration paths and the load pick up, in which loads are reconnected in small increments to avoid excessive frequency deviations and potential new system instabilities. Once this is achieved, the emerging subsystems must be re-synchronised and re-connected to enhance their stability margins. Thus, data collection and information processing is essential to properly run the PPSR process.

In [2], it has been stated that the two main methodologies for power system restoration after a partial or complete blackout are: the "build-down" strategy, which re-energises the network before re-synchronising generators, or the "build-up" strategy, which firstly restores the existing islands, and then apply the PPSR procedure. By sectionalising the system and by applying PPSR ("build up" methodology) is accepted as the dominating worldwide restoration scheme as it reduces the restoration duration.

The system separation (also known as islanding) into groups of generators can be in advance strategically planned, by identifying the coherent groups of generators,

This work was supported in part by the Engineering and Physica Science Research Council (EPSRC) in the UK and The University of Costa Rica.

J. Quirós Tortós, G. Valverde and V. Terzija are with the School of Electrical \& Electronic Engineering, The University of Manchester, Manchester, UK (e-mail: jairoquirostortos@ieee.org, gvalverde@ieee.org, vterzija@ieee.org).

L. Ding is with the School of Electrical Engineering, Shandong University, Jinan, China (e-mail: dinglei@sdu.edu.cn). and consequently, the weak connections between different islands. This approach is used to identify those power system islands with a minimum possible load-generation mismatch.

Nowadays, intelligent system splitting strategies are undertaken using different algorithms. For example, a real time approach for finding proper system splitting strategies using a three-phase Ordered Binary Decision Diagram (OBDD) method is proposed in [3]. Since this approach takes into consideration only steady-state constraints, an approach considering transient simulations is presented in [4]. In [5], a slow coherency technique is used to group both generators and load buses in a single group considering the closeness of each other. This approach uses the slow eigenbasis theory to collect coherent groups. This methodology determines the closeness of each load bus $j$ to the reference generator $i$. This is obtained by applying the cosine function of the angle between the two row vectors of the eigenbasis matrix corresponding to buses $i$ and $j$.

In [6], an analytical basis for the application of slow coherency method based on two-time scale theory is introduced. It includes a modification of tolerance based slow coherency to create islands in the system by employing an important control strategy to deal with large disturbances. A controlled islanding solution for large power systems verified by dynamic simulations is proposed in [7]. Here a graph representation of the system is used to simplify the structure of the power system. In [8], a method based on the weak coupling concept for identifying groups of slowly coherent generators is presented.

Methodologies for PMUs placement have been mainly proposed for state estimation purposes, i.e. to achieve full network observability during quasi-steady-state operating condition. However, a methodology for PMUs placement to ensure enough information during PPSR is still an unexplored research and practical engineering challenge.

In [9], a technique for identifying placement sites for PMUs in a power system based on incomplete observability is presented. The paper presents a novel concept of depth of unobservability. Initially, it uses the spanning tree of the power system graph and a tree search technique to find the optimal location of PMUs. Then, it extends the modelling to recognise limitations in the availability of communication facilities across the network and pose the constrained placement problem within the framework of simulated annealing. In [10], a Generalised Integer Linear Programming (GILP) formulation to place PMUs is proposed. Different scenarios, including redundant PMU placement, full observability and incomplete observability, 
were considered.

In order to solve the problem of the lack of information during PPSR, especially at boundary buses, this paper proposes a PMU placement method based on an ILP formulation across the identified weak areas of the power system. Results for the New England 39-bus test system are firstly presented to validate the proposed solution. In order to validate the new methodology in larger power systems, the results for the IEEE 118-bus test system are presented, as well.

Section II introduces the concept of slow coherency and weak connections. Furthermore, the concept of weak areas, based on the weak connections approach, is defined. Section III presents the ILP formulation to place PMUs across weak areas in the power system in order to have information during the PPSR process. The results of testing the new methodology are presented in Section IV. Finally, in Section $\mathrm{V}$ the conclusions drawn from the study are given.

\section{SLOW COHERENCY, WEAK CONNECTION AND WEAK AREA}

The close relationship between slow coherency and weak connection has been previously stated in [11]. The concept of slow coherency is based on the fact that groups of generators have a tendency to swing together following a disturbance in a multi-machine power system.

Slow coherency analysis solves the problem of theoretically identifying the weakest connections across the power system. These weakest connections are functions of the admittance matrix parameter, machine inertias and the initial rotor angles of the interconnected machines. Therefore, it can be noticed that the boundaries encountered for each island depend upon the inherent structural characteristics of the power system. In addition, these islands must be created considering the availability of intertie lines, a request for the load-generation balance and existence of Blackstart (BS) units within each island.

Based on the singular perturbation form, the slow coherency theory assumes that the state variables of an $n$-th order system are divided into $r$ slow states and $(n-r)$ fast states, namely $y$ and $z$, respectively. Where the $r$ slowest states represent $r$ groups with the slow coherency [11]. This can be expressed as follows:

$$
\begin{array}{ll}
\frac{d y}{d t}=f(y, z, t), & y\left(t_{0}\right)=y_{0} \\
\frac{d z}{d t}=G(y, z, t), & \mathrm{z}\left(t_{0}\right)=z_{0}
\end{array}
$$

Two assumptions are considered in order to carry out the slow coherency analysis [6]. The first one assumes that the coherent groups of generators are independent of the size of the disturbance; whilst the second considers that the coherent groups are independent of the level of detail used to model the generating units. According to the second assumption, the following simplified classical model of an $m$-machine power system can be used [12]:

$$
\begin{gathered}
\ddot{\mathbf{x}}=\mathbf{A} \mathbf{x}=\left(\mathbf{M}^{-1} \mathbf{K}\right) \mathbf{x} \\
\mathbf{x}=\left[\Delta \delta_{1}, \Delta \delta_{2}, \ldots, \Delta \delta_{m}\right]^{\mathrm{T}} \\
\mathbf{A}=\mathbf{M}^{-1} \mathbf{K}
\end{gathered}
$$

$$
\begin{gathered}
\mathbf{M}=\operatorname{diag}\left(2 H_{1} / \omega_{0}, 2 H_{2} / \omega_{0}, \ldots, 2 H_{m} / \omega_{0}\right) \\
K_{i j}= \begin{cases}-\left|V_{i}\right|\left|V_{j}\right|\left[\begin{array}{c}
B_{i j} \cos \left(\delta_{i}-\delta_{j}\right) \\
-G_{i j} \sin \left(\delta_{i}-\delta_{j}\right)
\end{array}\right], & i \neq j \\
-\sum_{l=1, l \neq i}^{n} K_{i l}, & i=j\end{cases}
\end{gathered}
$$

where $V_{i}$ and $V_{j}$ are the bus voltage magnitude at bus $i$ and $j$ respectively. $\delta_{i}$ is the rotor angle in radians and $H_{i}$ is the inertia constant in seconds of the $i$-th machine; $G_{i j}$ and $B_{i j}$ are the real and imaginary entries of the admittance matrix $\mathbf{Y}_{\text {bus }}$.

Another concern commonly related to the slow coherency analysis is the weak connection form. In fact, the slow coherency phenomenon occurs in dynamic networks when the connections between areas are weak [11]. A two area system is said to be weakly connected if its dynamic properties can be described by (8):

$$
\begin{aligned}
\mathcal{E}\left[\begin{array}{c}
\frac{d \mathbf{x}_{1}}{d t} \\
\frac{d \mathbf{x}_{2}}{d t}
\end{array}\right]=\left[\begin{array}{l}
\frac{d \mathbf{x}_{1}}{d \tau} \\
\frac{d \mathbf{x}_{2}}{d \tau}
\end{array}\right] & =\left[\begin{array}{cc}
\mathbf{A}_{11} & 0 \\
0 & \mathbf{A}_{22}
\end{array}\right]\left[\begin{array}{l}
\mathbf{x}_{1} \\
\mathbf{x}_{2}
\end{array}\right] \\
& +\varepsilon\left[\begin{array}{ll}
\mathbf{A}_{11}^{\prime} & \mathbf{A}_{12} \\
\mathbf{A}_{21} & \mathbf{A}_{22}^{\prime}
\end{array}\right]\left[\begin{array}{l}
\mathbf{x}_{1} \\
\mathbf{x}_{2}
\end{array}\right]
\end{aligned}
$$

where $\mathbf{x}_{1}$ and $\mathbf{x}_{2}$ are $n_{1}$ and $n_{2}$ column vectors, $\mathbf{A}_{11}, \mathbf{A}_{11}^{\prime}, \mathbf{A}_{12}$, $\mathbf{A}_{21}, \mathbf{A}_{22}, \mathbf{A}_{22}^{\prime}$ are matrices of order one without any zero entries, $\tau=\left(t-t_{0}\right) / \varepsilon$ and $\varepsilon$ is a small positive parameter in the slow coherency solution when the external connections are weak or sparse.

In [13], a linear analysis is carried out to prove that by selecting the $r$ slowest modes, the aggregated system will have the weakest connections between different groups of generators. The weak connection form best states the reason for islanding based on slow coherency grouping. Slow coherency is actually a physical manifestation of a weak connection which is an inherent network characteristic.

In real large scale power systems, there always exist groups of strongly interacting units with weak connections between groups or areas. When a large disturbance occurs, it is imperative to disconnect these weak connections before the slow interaction becomes significant.

Weak connection is a system property which is independent of operating conditions or the degree of modelling. The methodology for system splitting based on weak connections minimises the dynamic coupling between islands according to the following formula:

$$
\min \left(\begin{array}{l}
\underbrace{\sum_{v_{m} \in \mathbf{V}_{G}^{l}, v_{n} \in \mathbf{V}_{G}^{k}, l \neq k} \frac{1}{2}\left(\frac{\partial P_{m n}}{\partial \theta_{m n}}\right)\left(\frac{1}{H_{m}}+\frac{1}{H_{n}}\right)}_{\Psi_{1}}) \\
+\underbrace{\sum_{v_{i} \in \mathbf{V}_{L}^{l}, v_{j} \in \mathbf{V}_{L}^{k}, l \neq k}\left(\frac{\partial P_{i j}}{\partial \theta_{i j}}\right)}_{\Psi_{2}})
\end{array}\right)
$$

where $\psi_{1}$ denotes the dynamic coupling between generators, which is normalised by the inertias and $\psi_{2}$ denotes the dynamic coupling between load buses. In (9), $V_{G}^{l}$ and $V_{G}^{k}$ represent the group of voltages at generator buses within 
islands $l$ and $k$, respectively. $V_{L}^{l}$ and $V_{L}^{k}$ represent the group of voltages at load buses within islands $l$ and $k$, respectively.

One of the major issues linked to the weak connections theory (9) is the identification of only one possible splitting strategy. To solve this problem and based on the eigenbasis matrix of the power system, this paper defines weak areas as the areas from the weak connections points up to a predefined threshold. This methodology provides several options to split the power system into smaller subsystems across these regions. The procedure of identifying the splitting options across the weak areas allows determining different possibilities of splitting strategies across these weak areas before the system reaches the total blackout. The placement of synchronised measurements across the weak areas can be used to ensure sufficient information during PPSR, independently of the splitting strategy perform across these areas.

By computing the eigenbasis matrix, the proposed methodology evaluates the closeness of each bus $j$ with respect to the reference bus $i$. This is obtained by applying the cosine function of the angles between the two row vectors of the eigenbasis matrix corresponding to buses $i$ and $j$. This approach is more clearly explained using the IEEE 9-bus test system shown in Fig. 1 [14]. After applying the slow coherency analysis [11], generators 2 and 3 are determined as coherent generators. Consequently, the other group is only generator 1 . By applying the weak connection algorithm (9), it can be determined that the weak connections are lines 4-6 and 4-5. Here, it is assumed that generators 1 and 2 are BS units.

The weak connections algorithm (9) can be further extended to determine the weak areas. This is achieved by defining a threshold, in the eigenbasis matrix, beyond the weak connections of, let say, 20 per cent (10 per cent on each side of the weak connection), as shown in Fig. 1, in which, the load buses are attached to the reference group.

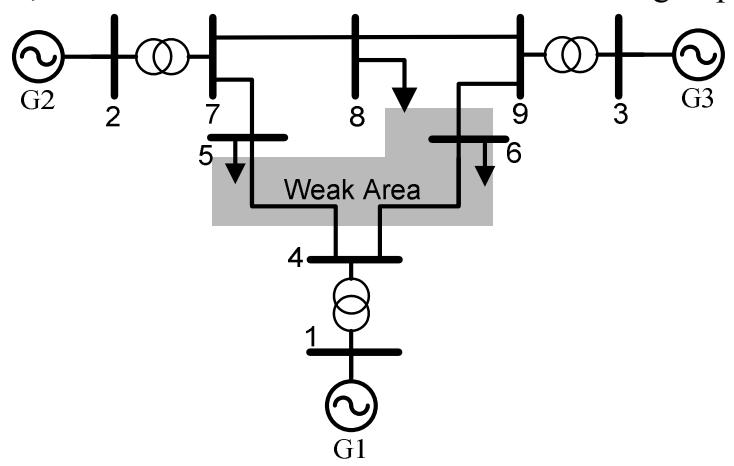

Fig.1. Single line diagram of the IEEE 9-bus test system with the identified weak area

\section{Minimal PMU Placement Across the WeAK AREA IN A POWER SYSTEM}

Synchronised measurement technology has become an attractive solution in modern power systems because it provides voltage and current phasors and frequency information across the system, all synchronised with high precision to a common time reference provided by a Global Positioning System (GPS) [9]. In order to obtain information about the actual state of the boundary buses during the restoration process, a methodology to place minimum PMUs across the splitting options, i.e. across the weak areas, is required.

The objective of the PMU placement problem is to achieve this task with a minimal number of devices. In this paper, the number of PMUs that are placed across the identified weak areas is minimised, while ensuring there is sufficient information during PPSR. This problem is solved by an ILP formulation and it takes advantage of zero injection buses to reduce the number of PMUs. Without loss of generality, it is assumed that every PMU has a sufficient number of channels to measure the current phasors through all the branches incident to the corresponding PMU buses (i.e. the busses in which PMUs are installed). This paper does not consider conventional measurements; it is rather a pure PMU solution, taking the advantage of unique high reporting rates possessed by the PMUs.

A binary variable vector $\mathbf{y}$, which represents the presence of PMUs across the weak areas in the power system, is defined. Considering this, the $i$-th entry of $\mathbf{y}$ is defined as:

$$
y_{i}= \begin{cases}1, & \text { if a PMU is placed at boundary bus } i \\ 0, & \text { otherwise }\end{cases}
$$

For an $n$-bus system separated into $r$ islands, the PMU placement problem can be formulated as follows:

$$
\min \sum_{i=1}^{n} c_{i} \cdot y_{i}
$$

subject to:

$$
f(\mathbf{Y}) \geq\left[\begin{array}{llll}
1 & 1 & \cdots & 1
\end{array}\right]_{n \times 1}^{T}
$$

where $c_{i}$ is the cost of the PMU installed at bus $i, f(\mathbf{Y})=\mathbf{B} \times \mathbf{y}$ and $\mathbf{B}=\left[b_{i j}\right]$ is the network connectivity matrix across the identified weak areas defined as follows:

$$
b_{i j}= \begin{cases}1, & \text { if } i=j \\ 1, & \text { if } i \text { and } j \text { are connected } \\ 0, & \text { otherwise }\end{cases}
$$

Considering the weak areas shown in Fig. 1 for the IEEE 9-bus system, the PMUs must be placed at buses 4 and 8 to have information during its PPSR. Placing PMUs at these buses allows collecting information about the boundary buses states during the restoration process.

\section{Simulation Results}

The proposed PMU placement method is demonstrated and validated using the New England 39-bus test system and the IEEE 118-bus test systems. To determine the number of coherent generator groups, this paper considers the minimal number of either the first largest gap between two eigenvalues $\lambda_{\mathrm{r}}$ and $\lambda_{\mathrm{r}+1}$ [11], where (14) is satisfied, or the number of available BS units:

$$
\left|\lambda_{i}\right| \leq\left|\lambda_{i+1}\right| \quad i=1,2, \ldots, n
$$

\section{A. Test case I: New England 39-bus test system}

The single line diagram of the New England 39-bus test system is presented in Fig. 2. This system has 10 synchronous generators, 34 transmission lines, 12 transformers and 19 constant power loads [5]. In this paper, 
it is assumed that generators 4,9 and 10 are BS units. Generator data are provided in the Appendix. From the eigenvalues analysis, it is concluded that the first largest gap between two consecutive values are found between the third and the fourth one. Thus, and taking into account the number of available BS units (three for this test case), the New England 39-bus must be split into three subsystems.

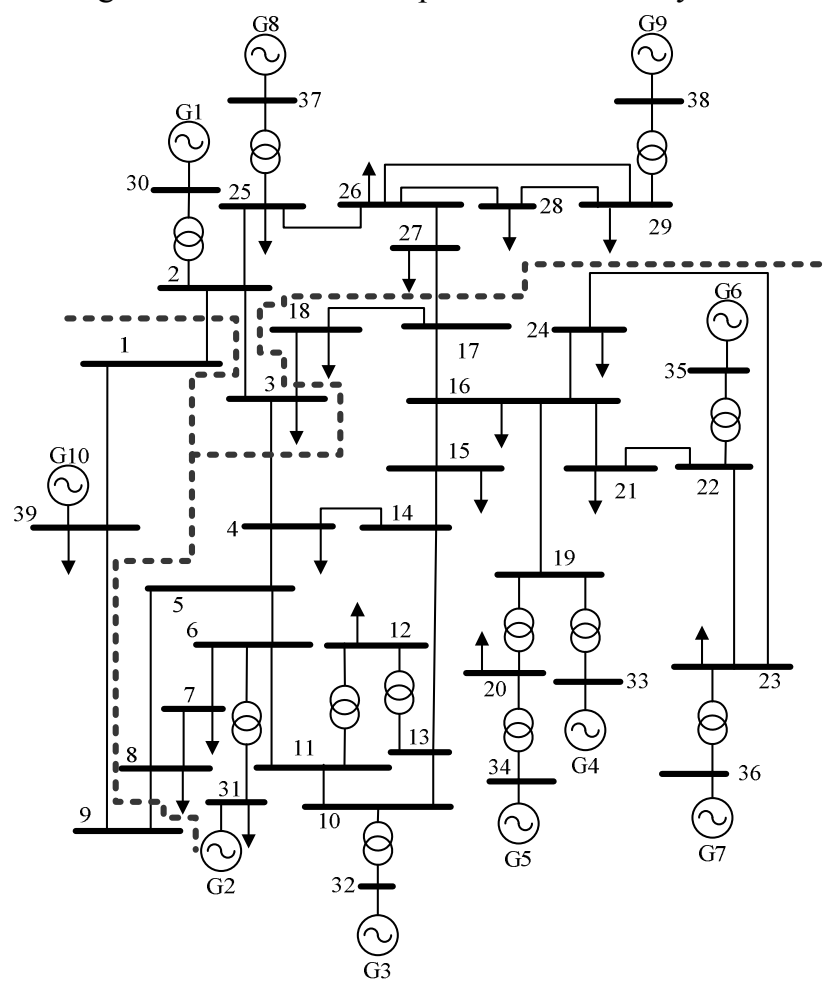

Fig.2. Single line diagram of the New England 39-bus test system

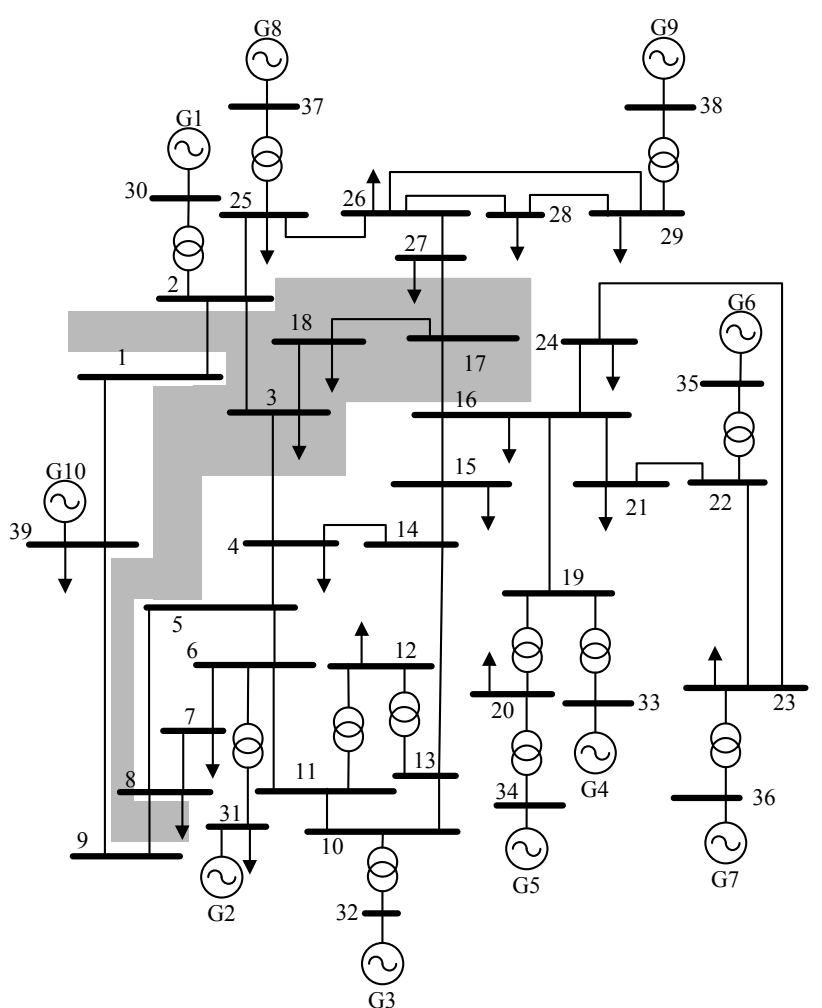

Fig.3. Single line diagram of the New England 39-bus test system with the identified weak areas

Considering the number of areas previously determined, the slow coherency algorithm [11] is performed and the coherent generator groups are shown in Table I.

TABLE I

Coherent Generator Groups For THE NEW England 39-Bus Test SYSTEM SPLIT INTO 3 SUBSYSTEMS

\begin{tabular}{|c|c|c|}
\hline Gen. No. for Group 1 & Gen. No. for Group 2 & Gen. No. for Group 3 \\
\hline $1,8,9$ & $2,3,4,5,6,7$ & 10 \\
\hline
\end{tabular}

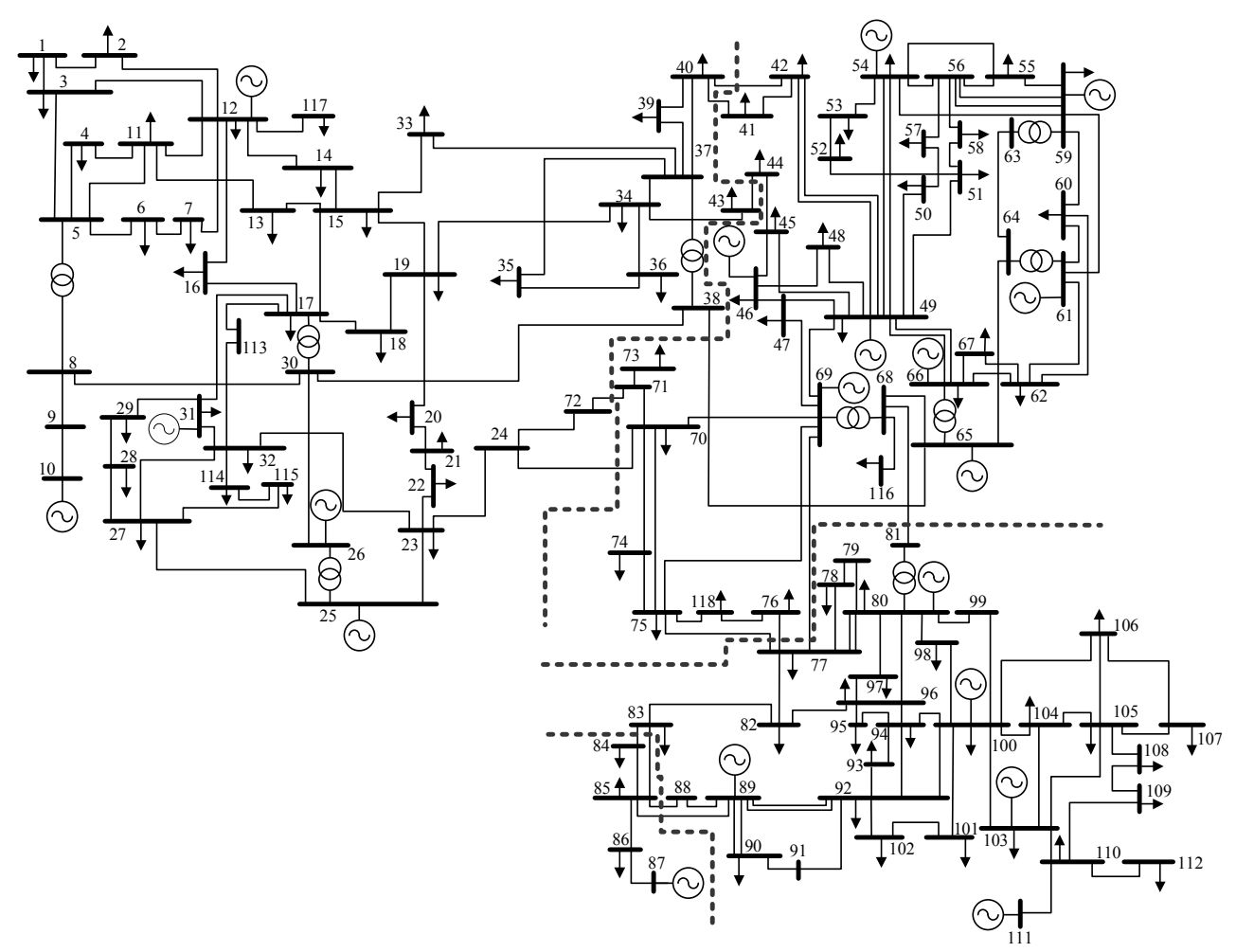

Fig. 4. Single line diagram of the IEEE 118-bus test system 
Using the weak connection algorithm (9) described in this paper, the system splitting strategy can be identified. The weak connections are determined as the following transmission lines (also shown in Fig. 2): 1-2, 3-4, 3-18, 8-9 and $17-27$. As it can be noticed, using this splitting strategy each island has at least one BS unit.

Once the weak connections are known, and using the obtained power system eigenbasis matrix, a threshold of 15 percent ( 7.5 per cent on each side of the weak connections) is defined to determine the weak areas. For the New England 39-bus, the weak areas are presented in Fig. 3.

\section{TABLE II}

OPTIMAL PMU PLACEMENT TO IMPROVE THE PPSR FOR THE NEW

\begin{tabular}{|c|c|} 
ENGLAND 39-BUS TEST SYSTEM \\
\hline System & Bus \\
\hline New England 39-bus & $4,17,20,25,26,39$ \\
\hline
\end{tabular}

As it can be observed, this method to identify the weak areas can provide different splitting options. By considering these weak areas, PMUs are optimally placed while ensuring sufficient information is available during PPSR. This is carried out independent of the splitting strategy across the weak areas. Table II presents the list of buses at which PMUs are placed.

\section{B. Test case II: IEEE 118-bus test system}

The second test system used to demonstrate the efficiency of the proposed methodology is the IEEE 118bus. The topology of the system is shown in Fig. 4. This test system contains 19 synchronous generators, 177 transmission lines, 9 transformers and 91 constant power loads [15]. Generator data are provided in the Appendix. This paper considers generators 10, 25, 69, 87 and 89 as BS units.
TABLE III

SEPARATION OF EIGENVALUES FOR THE IEEE 118-Bus TeST System

\begin{tabular}{|c|c|c|}
\hline & $\begin{array}{c}\text { Eigenvalues } \\
\left(f_{i}\right)\end{array}$ & $\varepsilon_{i}=f_{i} / f_{i+1}$ \\
\hline 1 & $\pm \mathrm{j} 0.00000$ & 0.000000 \\
\hline 2 & $\pm \mathrm{j} 0.11276$ & 0.716518 \\
\hline 3 & $\pm \mathrm{j} 0.15737$ & 0.800641 \\
\hline 4 & \pm j 0.19656 & 0.709788 \\
\hline 5 & $\pm \mathbf{j} 0.27692$ & 0.862132 \\
\hline 6 & $\pm \mathrm{j} 0.32121$ & 0.911838 \\
\hline 7 & $\pm \mathrm{j} 0.35226$ & 0.769798 \\
\hline 8 & $\pm \mathrm{j} 0.45760$ & 0.862026 \\
\hline 9 & $\pm \mathrm{j} 0.53085$ & 0.725376 \\
\hline 10 & $\pm \mathrm{j} 0.73182$ & 0.948589 \\
\hline 11 & $\pm \mathrm{j} 0.77149$ & 0.919699 \\
\hline 12 & $\pm \mathrm{j} 0.83885$ & 0.841307 \\
\hline 13 & $\pm \mathrm{j} 0.99708$ & 0.797392 \\
\hline 14 & $\pm \mathrm{j} 1.25042$ & 0.97812 \\
\hline 15 & $\pm \mathrm{j} 1.27839$ & 0.757293 \\
\hline 16 & $\pm \mathrm{j} 1.68811$ & 0.865859 \\
\hline 17 & $\pm \mathrm{j} 1.94963$ & 0.880022 \\
\hline 18 & $\pm \mathrm{j} 2.21543$ & 0.791465 \\
\hline 19 & $\pm \mathrm{j} 2.79916$ & \\
\hline
\end{tabular}

As it can be noticed from Table III, the first largest gap between two consecutive eigenvalues is obtained after the fourth eigenvalue. Therefore, the proposed algorithm splits the system into four subsystems. The coherent generator groups, obtained from the slow coherency algorithm [11], are shown in Table IV.

TABLE IV

COHERENT GENERATOR GROUPS FOR THE IEEE 118-Bus TEST SYSTEM SPLIT INTO 4 SUBSYSTEMS

\begin{tabular}{|c|c|c|c|}
\hline $\begin{array}{c}\text { Gen. No. for } \\
\text { Group 1 }\end{array}$ & $\begin{array}{c}\text { Gen. No.for } \\
\text { Group 2 }\end{array}$ & $\begin{array}{c}\text { Gen. No.for } \\
\text { Group 3 }\end{array}$ & $\begin{array}{c}\text { Gen. No. for } \\
\text { Group 4 }\end{array}$ \\
\hline $10,12,25$, & $46,49,54,59$, & 87 & $80,89,100$, \\
26,31 & $61,65,66,69$ & & 103,111 \\
\hline
\end{tabular}

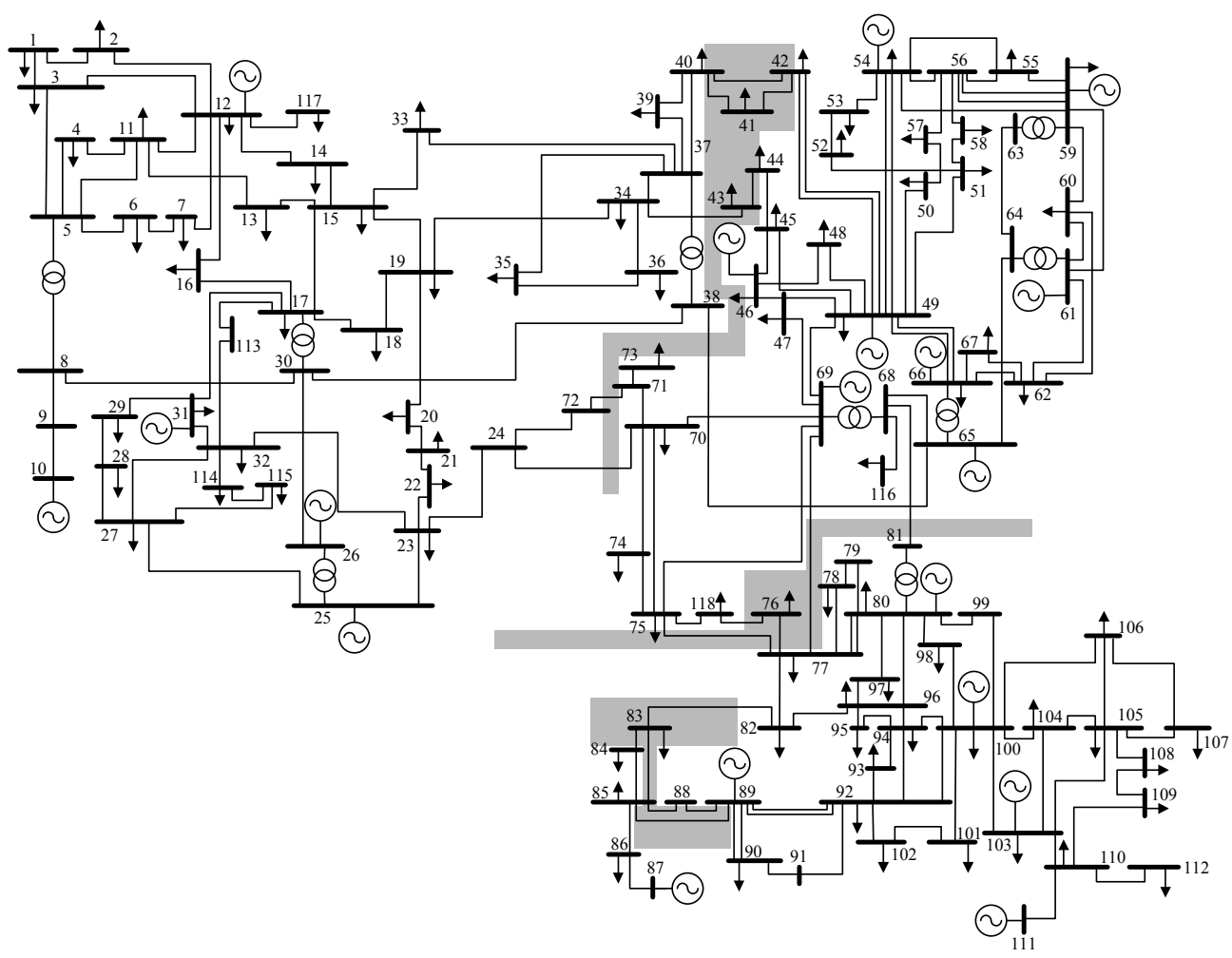

Fig. 5. Single line diagram of the IEEE 118-bus test system with the identified weak areas 
TABLE V

WEAK CONNECTIONS FOR THE IEEE 118 -BUS TEST SYSTEM

\begin{tabular}{|c|c|}
\hline Cutset & Lines \\
\hline 1 & $24-70 ; 71-72 ; 38-65 ; 43-44 ; 40-41 ; 40-42$ \\
\hline 2 & $75-77 ; 76-77 ; 69-77 ; 68-81$ \\
\hline 3 & $83-84 ; 83-85 ; 85-88 ; 85-89$ \\
\hline
\end{tabular}

TABLE VI

OPTIMAL PMU PLACEMENT TO IMPROVE THE PPSR FOR THE IEEE 118 BUS TEST SYSTEM

\begin{tabular}{|c|c|}
\hline System & Bus \\
\hline \multirow{2}{*}{ IEEE 118-bus } & $24,34,40,42,44,65,70$, \\
& $77,80,82,85,89,118$ \\
\hline
\end{tabular}

The weak connections for this test system have been identified (see Table V and dashed line in Fig. 4) and the weak areas across them have been defined as a threshold of 20 percent (10 per cent on each side of the weak connections) as presented in Fig. 5.

It is important to understand that the proposed algorithm defines the islands with at least one BS unit. Considering the weak areas, the PMUs must be placed in order to ensure information during PPSR considering all the possible splitting strategies. The optimal placement of these units is presented in Table VI.

The PMU location configuration in Table VI ensures that all the boundary buses are being monitored by at least one PMU (or at least the state of the bus can be obtained from the state estimator). This allows collection of important data regarding frequencies, angles and voltage magnitudes of the boundary buses before and after the reconnection of the islands.

\section{CONCLUSION}

A methodology to place the minimum number of phasor measurement units across the weak areas to monitor the boundary buses during the parallel power system restoration is presented in this paper. Weak areas across the power system are determined to point out different splitting options instead of a singular splitting strategy. The proposed optimal placement of PMUs allows the power system operator to speed up the restoration process as more information is available independent of the splitting strategy performed across these weak areas. The algorithm was demonstrated and validated in two different test systems. The PMU placement ensures that the operating conditions of all the boundary buses will be known during the parallel power system restoration.

\section{APPENDIX}

The appendix presents generator data (on a 100 MVA base) of the three test systems used in this paper.

TABLE VII

GENERATOR DATA FOR THE IEEE 9-BUS TEST SySTEM [14

\begin{tabular}{|c|c|c|c|c|c|}
\hline $\begin{array}{c}\text { Gen. } \\
\text { No. }\end{array}$ & $\begin{array}{c}M_{i} \\
(\mathrm{~s})\end{array}$ & $\begin{array}{c}x_{d, i}^{\prime} \\
(\mathrm{p} . \mathrm{u})\end{array}$ & $\begin{array}{c}\text { Gen. } \\
\text { No. }\end{array}$ & $\begin{array}{c}M_{i} \\
(\mathrm{~s})\end{array}$ & $\begin{array}{c}x_{d, i}^{\prime} \\
(\mathrm{p} . \mathrm{u})\end{array}$ \\
\hline 1 & 47.28 & 0.0608 & 3 & 6.02 & 0.1813 \\
\hline 2 & 12.8 & 0.1198 & \multicolumn{3}{|c}{} \\
\cline { 1 - 3 }
\end{tabular}

TABLE VIII

Generator Data FOR THE NeW ENGLAND 39-Bus TeSt System [5]

\begin{tabular}{|c|c|c|c|c|c|}
\hline $\begin{array}{c}\text { Gen. } \\
\text { No. }\end{array}$ & $\begin{array}{c}M_{i} \\
(\mathrm{~s})\end{array}$ & $\begin{array}{c}x_{d, i}^{\prime} \\
(\mathrm{p} . \mathrm{u})\end{array}$ & $\begin{array}{c}\text { Gen. } \\
\text { No. }\end{array}$ & $\begin{array}{c}M_{i} \\
(\mathrm{~s})\end{array}$ & $\begin{array}{c}x_{d, i}^{\prime} \\
(\mathrm{p} . \mathrm{u})\end{array}$ \\
\hline 1 & 84.0 & 0.0310 & 6 & 69.6 & 0.0500 \\
\hline 2 & 60.6 & 0.0697 & 7 & 52.8 & 0.0490 \\
\hline 3 & 71.6 & 0.0531 & 8 & 48.6 & 0.0570 \\
\hline 4 & 53.6 & 0.0436 & 9 & 69.0 & 0.0570 \\
\hline 5 & 52.0 & 0.1320 & 10 & 1000.0 & 0.0060 \\
\hline
\end{tabular}

For the IEEE 118-bus test system, generator data were selected according to the typical generator data presented in [12].

TABLE IX

GENERATOR DATA FOR THE IEEE 118-BUS TEST SYSTEM

\begin{tabular}{|c|c|c|c|c|c|}
\hline $\begin{array}{c}\text { Gen. } \\
\text { No. }\end{array}$ & $\begin{array}{c}M_{i} \\
(\mathrm{~s})\end{array}$ & $\begin{array}{c}x_{d, i}^{\prime} \\
(\mathrm{p} . \mathrm{u})\end{array}$ & $\begin{array}{c}\text { Gen. } \\
\text { No. }\end{array}$ & $\begin{array}{c}M_{i} \\
(\mathrm{~s})\end{array}$ & $\begin{array}{c}x_{d, i}^{\prime} \\
(\mathrm{p} . \mathrm{u})\end{array}$ \\
\hline 10 & 23.800 & 0.0592 & 65 & 30.374 & 0.0668 \\
\hline 12 & 9.970 & 0.2200 & 66 & 30.374 & 0.0668 \\
\hline 25 & 19.210 & 0.1391 & 69 & 26.944 & 0.0527 \\
\hline 26 & 19.840 & 0.0961 & 80 & 26.944 & 0.0527 \\
\hline 31 & 9.280 & 0.2467 & 87 & 9.280 & 0.2467 \\
\hline 46 & 9.280 & 0.2467 & 89 & 27.360 & 0.0475 \\
\hline 49 & 19.210 & 0.1391 & 100 & 22.300 & 0.0948 \\
\hline 54 & 9.970 & 0.2200 & 103 & 9.970 & 0.2200 \\
\hline 59 & 12.680 & 0.1531 & 111 & 9.970 & 0.2200 \\
\hline 61 & 12.680 & 0.1531 & \multicolumn{3}{|l}{} \\
\hline \multicolumn{7}{|c|}{}
\end{tabular}

\section{REFERENCES}

IEEE PES Power System Engineering Committee, "Special considerations in power system restoration," IEEE Transactions on Power Systems, vol. 7, no. 4, pp. 1419-1427, Nov. 1992.

[2] M.M. Adibi and L.H. Fink, "Power system restoration planning," IEEE Transactions on Power Systems, vol. 9, no. 1, pp. 22-28 Feb. 1994.

[3] K. Sun, D. Zheng and Q. Lu, "Splitting strategies for islanding operation of large-scale power systems using OBDD-based methods," IEEE Transactions on Power Systems, vol. 18, no. 2, pp. 912-922, May 2003

[4] K. Sun, D. Zheng and Q. Lu, "A simulation study of OBDDbased proper splitting strategies for power systems under consideration of transient stability," IEEE Transactions on Power Systems, vol. 20, no. 1, pp. 389-399, Feb. 2005.

[5] S.B. Yusof, G.J. Rogers and R.T.H. Alden, "Slow coherency based network partitioning including load buses," IEEE Transactions on Power Systems, vol. 8, no. 3, pp. 1375-1382, Aug. 1993.

[6] H. You, V. Vittal and X. Wang, "Slow coherency - Based islanding," IEEE Transactions on Power Systems, vol. 19, no. 1, pp. 483-491, Feb. 2004.

[7] G. Xu and V. Vittal, "Slow coherency based cutset determination algorithm for large power systems," IEEE Transactions on Power Systems, vol. 25, no. 2, pp. 877-884, May. 2010

[8] S.S. Lamba and R. Nath, "Coherency identification by the method of weak coupling," Electrical Power \& Energy Systems, vol. 7, no. 4, pp. 233-242, Oct. 1985.

[9] R.F. Nuqui and A.G. Phadke, "Phasor Measurement Unit placement techniques for complete and incomplete observability," IEEE Transactions on Power Delivery, vol. 20, no. 4, pp. 2381-2388, Oct. 2005.

[10] B. Guo, "Generalized integer linear programming formulation for optimal PMU placement," IEEE Transactions on Power Systems, vol. 23, no. 3, pp. 1099-1104, Aug. 2008.

[11] J.H. Chow, Time-Scale Modeling of Dynamic Networks with Applications to Power Systems vol. 46. New York: SpringerVerlag, 1982.

[12] P.M. Anderson and A.A. Fouad, Power System Control and Stability, $2^{\text {nd }}$ ed. New York: IEEE Press, 2003.

[13] R.A. Date and J.H. Chow, "Aggregation properties of linearized two-time-scale power networks," IEEE Transactions on Circuits and Systems, vol. 38, no. 7, pp. 720-730, Jul. 1991.

[14] P.W. Sauer and M.A. Pai, Power System Dynamic and Stability. New Jersey: Prentice Hall, 1998.

[15] University of Washington, "Power system test case archive," available at: http://www.ee.washington.edu/research/pstca/, consulted in Oct. 2010. 


\section{BIOGRAPHIES}

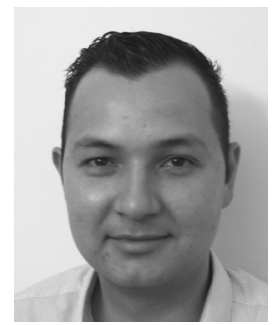

Jairo H. Quirós Tortós (S’08) was born in Limón, Costa Rica. He obtained the B.Sc. and Licentiate degree with honours in Electrical Engineering from the University of Costa Rica, San Pedro, Costa Rica in 2008 and 2009 respectively. Currently he is a Ph.D. student at The University of Manchester, working on power system restoration and intelligent controlled islanding for power system. His main research interests are application of intelligent methods to power system restoration, and controlled islanding, power system monitoring, protection and control, voltage stability assessment, and power system dynamics. At the end of his Ph.D. studies, he hopes to return to the University of Costa Rica as a Professor and Researcher.

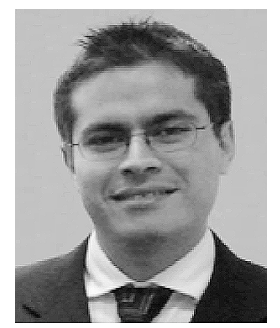

Gustavo Valverde (S'08) received the B.Sc. degree in electrical engineering from the University of Costa Rica, San Pedro, in 2005 and the M.Sc. degree in electrical power systems from the University of Manchester, Manchester, U.K., in 2008. Currently, he is pursuing the Ph.D. degree at The University of Manchester, working on state and parameter estimators for power system applications. His research interests include monitoring of power systems, probabilistic analysis in power systems, state and parameter estimation, dynamics, and voltage stability assessment.

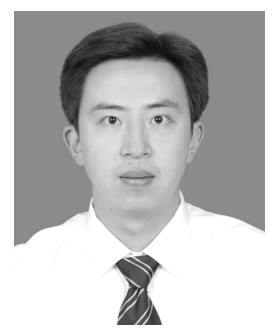

Lei Ding (M'2010) was born in Shandong, China, in 1980. He received the B.E. and Ph.D. degrees from Shandong University in 2001 and 2007, respectively, in electrical engineering. His research interests include power system wide area protection and Microgrid protection. From 2008 to 2009 , he was a postdoctoral researcher in Tsinghua University, China. From 2010 to 2011, he worked in the School of Electrical and Electronic Engineering, The University of Manchester as a Research Associate. Currently he is an associate professor in the School of Electrical Engineering, Shandong University, China.

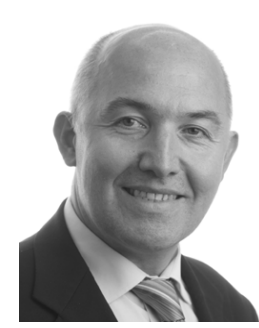

Vladimir Terzija (M'95, SM'2000) is the EPSRC Chair Professor in Power System Engineering in the School of Electrical and Electronic Engineering, The University of Manchester, where he has been since 2006. From 1997 to 1999, he was an Assistant Professor at the University of Belgrade. In 1999, he was awarded a prestigious Humboldt Research Fellowship. From 2000 to 2006, he was with ABB AG, Germany, working as an expert for switchgear and distribution automation. His main research interests are application of intelligent methods to power system monitoring, control, and protection, switchgear and fast transient processes, as well as DSP applications in power systems. 